Article

\title{
Cardiotoxic Effects of Short-Term Doxorubicin Administration: Involvement of Connexin 43 in Calcium Impairment
}

\author{
Michela Pecoraro ${ }^{1}$, Antonio Rodríguez-Sinovas ${ }^{2}$, Stefania Marzocco ${ }^{1}$ (D), Michele Ciccarelli ${ }^{3}$, \\ Guido Iaccarino ${ }^{3}$, Aldo Pinto ${ }^{1}$ and Ada Popolo ${ }^{1, *}$ (D) \\ 1 Department of Pharmacy, University of Salerno, Fisciano (SA) 84084, Italy; mipecoraro@unisa.it (M.P.); \\ smarzocco@unisa.it (S.M.); pintoal@unisa.it (A.P.) \\ 2 Cardiovascular Diseases Research Group, Department of Cardiology, Vall d'Hebron University Hospital and \\ Research Institute, Universitat Autònoma de Barcelona (UAB), Barcelona 08035, Spain; \\ antonio.rodriguez.sinovas@vhir.org \\ 3 Department of Medicine and Surgery, University of Salerno, Baronissi (SA) 84084, Italy; \\ mciccarelli@unisa.it (M.C.); giaccarino@unisa.it (G.I.) \\ * Correspondence: apopolo@unisa.it; Tel.: +39-089-969796
}

Received: 8 September 2017; Accepted: 9 October 2017; Published: 11 October 2017

\begin{abstract}
The use of Doxorubicin (DOXO), a potent antineoplastic agent, is limited by the development of cardiotoxicity. DOXO-induced cardiotoxicity is multifactorial, although alterations in calcium homeostasis, seem to be involved. Since even the Connexin43 (Cx43) plays a pivotal role in these two phenomena, in this study we have analyzed the effects of DOXO on Cx43 expression and localization. Damage caused by anthracyclines on cardiomyocytes is immediate after each injection, in the present study we used a short-term model of DOXO-induced cardiomyopathy. C57BL/6j female mice were randomly divided in groups and injected with DOXO (2 or $10 \mathrm{mg} / \mathrm{kg}$ i.p.) for $1-3$ or 7 days once every other day. Cardiac function was assessed by Echocardiography. Sarco/endoplasmic reticulum $\mathrm{Ca}^{2+}$-ATPase (SERCAII) and phospholamban (PLB) expression were assessed by Western blot analysis, intracellular $\left[\mathrm{Ca}^{2+}\right]$ were detected spectrofluorometrically by means of Fura-2 pentakis (acetoxymethyl) ester (FURA-2AM), and Cx43 and pCx43 expression and localization was analyzed by Western blot and confirmed by immunofluorescence analysis. DOXO induces impairment in $\mathrm{Ca}^{2+}$ homeostasis, already evident after a single administration, and affects $\mathrm{Cx} 43$ expression and localization. Our data suggest that DOXO-induced alterations in $\mathrm{Ca}^{2+}$ homeostasis causes in the cells the induction of compensatory mechanisms until a certain threshold, above which cardiac injury is triggered.
\end{abstract}

Keywords: connexin 43; doxorubicin; cardiotoxicity; calcium homeostasis; mitochondria

\section{Introduction}

Doxorubicin (DOXO) is a potent broad-spectrum antineoplastic drug, but the development of acute and chronic cardiotoxicity limits its clinical utility [1]. DOXO-induced cardiotoxicity comprise disturbances in cardiac rhythm [2], changes in blood pressure [3], reduction of ejection fraction and contractile function [4], cardiac dilation [5], and cardiomyopathy [6], are often not clinically evident until the late stages. DOXO-induced cardiotoxicity is mainly related to accumulation of the repetitive doses required by the treatments; total DOXO cannot exceed $500 \mathrm{mg} / \mathrm{m}^{2}$, but recent evidence indicates that the damage caused by anthracyclines on cardiomyocytes is an early event, already evident after a single administration $[7,8]$.

The exact pathogenesis of DOXO-induced cardiotoxicity is not fully understood even if it is assumed that it is multifactorial [9-12]. Several lines of evidence indicate that DOXO-induced 
cardiomyopathy is characterized by abnormal calcium homeostasis, but most of the studies published report only the effects of long-term DOXO-administration [13-16]. Recently, we have demonstrated that DOXO administration is able to induce calcium dysregulation and Connexin43 (Cx43) re-arrangement in a rat cardiomyoblast cell line already evident after a short-term administration [17]. Cx43 is the most abundant gap junction protein in the heart [18], where it is involved in transcellular electrical conduction and cell survival. In the heart, gap junctions are responsible for the cell-to-cell connection and the propagation of the electrical potential between cardiomyocytes and synchronous contraction [19]. Alterations in Cx43 expression and/or distribution are common features in cardiovascular diseases, i.e., in hypertrophic cardiomyopathy, heart failure and ischemia [20-22]. Cx43 is a phosphoprotein and phosphorylation on each of its phosphorylation sites affects membrane insertion and degradation [23,24], and shapes the open probability of the pore [25]. The phosphoproteins arranged in a slightly twisted conformation, highly susceptible to intracellular $\mathrm{Ca}^{2+}$, maintain pore patency; increase in intracellular $\mathrm{Ca}^{2+}$ results in closure of the pores [26]. Besides its role in plasma membrane, mitochondrial Cx43 (mCx43) has demonstrated a central role in cardioprotection [27]. Cx43 is functionally associated with calcium [28]. Furthermore, it has been demonstrated that $\mathrm{C} \times 43$ remodelling might be responsible for intracellular calcium overloading [29], thus resulting in ischemic arrhythmia [30]. As cardiotoxic effects of DOXO imply dysfunction in calcium homeostasis, we hypothesized that DOXO-induced toxicity could also involve Cx43. The aim of this study was to investigate the effects of DOXO administration on Cx43 expression and localization and on calcium homeostasis in a short-term model of DOXO-induced cardiotoxicity in mice.

\section{Results}

\subsection{Cardiac Functions}

Mice were subjected to echocardiography at baseline and before the sacrifice to analyze the main parameters of cardiac function. As reported in Table 1, DOXO administration affects EF, FS, LVEDD, LVESD, and IVSs in mice after a single injection of DOXO. Indeed, compared with control mice, DOXO-treated mice exhibited decreased cardiac systolic function as measured by EF, FS, and IVSD, consequently increased LVEDP and LVESD.

Table 1. Effect of Doxorubicin DOXO (2 or $10 \mathrm{mg} / \mathrm{kg}$; i.p.) on left ventricular end diastolic diameter (LVEDD), left ventricular end systolic diameter (LVESD), ejection fraction (\% EF), and fraction shortening (\% FS) after a single administration (1st group), two administrations (2nd group), or three administrations (3rd group). Results were expressed as mean \pm S.E.M. from 6 mice/group.

\begin{tabular}{|c|c|c|c|c|}
\hline Groups & Parameters & Control & $2 \mathrm{mg} / \mathrm{kg}$ & $10 \mathrm{mg} / \mathrm{kg}$ \\
\hline \multirow{4}{*}{ 1st group } & LVEDD & $3.97 \pm 0.11$ & $3.92 \pm 0.11$ & $4.09 \pm 0.10$ \\
\hline & LVESD & $2.62 \pm 0.17$ & $2.77 \pm 0.09$ & $3.00 \pm 0.06^{*}$ \\
\hline & $\%$ EF & $62.17 \pm 4.1$ & $58.39 \pm 1.12 *$ & $52.7 \pm 1.38^{* *}$ \\
\hline & $\% \mathrm{FS}$ & $30.41 \pm 0.72$ & $33.26 \pm 2.93$ & $26.76 \pm 0.92 *$ \\
\hline \multirow{4}{*}{ 2nd group } & LVEDD & $3.94 \pm 0.05$ & $3.87 \pm 0.05$ & $3.99 \pm 0.06$ \\
\hline & LVESD & $2.78 \pm 0.054$ & $2.78 \pm 0.05$ & $2.90 \pm 0.06^{*}$ \\
\hline & $\% \mathrm{EF}$ & $57.2 \pm 1.25$ & $54063 \pm 1.6^{*}$ & $53.73 \pm 1.61 *$ \\
\hline & $\%$ FS & $30.41 \pm 0.85$ & $27.95 \pm 1.06^{*}$ & $27.43 \pm 1.02 *$ \\
\hline \multirow{4}{*}{ 3rd group } & LVEDD & $3.86 \pm 0.04$ & $3.94 \pm 0.07$ & $3.96 \pm 0.06^{*}$ \\
\hline & LVESD & $2.73 \pm 0.15$ & $2.85 \pm 0.06$ & $2.9 \pm 0.14 *$ \\
\hline & $\%$ EF & $59.00 \pm 4.17$ & $54.4 \pm 2.6^{*}$ & $50.49 \pm 4.79 * *$ \\
\hline & $\% \mathrm{FS}$ & $31.76 \pm 1.68$ & $30.97 \pm 2.91$ & $25.37 \pm 3.02 *$ \\
\hline
\end{tabular}

\subsection{Doxorubicin Administration Alters Calcium Homeostasis}

It is well known that impairment in $\left[\mathrm{Ca}^{2+}\right]_{i}$ plays a pivotal role both in cardiotoxic activity of DOXO [1] and in Cx43 activity [29]. In order to evaluate the effects of DOXO treatment on intracellular $\mathrm{Ca}^{2+}$ levels in our experimental model, primary cardiomyocytes from hearts of DOXO-treated mice and from control mice were isolated and loaded with the fluorescent dye FURA2-AM in $\mathrm{Ca}^{2+}$-free 
incubation medium (containing $0.5 \mathrm{mM}$ EGTA). Our data indicate that DOXO treatment increased basal level of $\left[\mathrm{Ca}^{2+}\right]_{\mathrm{i}}$. Indeed the delta increase in $\left[\mathrm{Ca}^{2+}\right]_{\mathrm{i}}$ induced by ionomycin, a Ca ${ }^{2+}$ ionophore, in cardiomyocytes from DOXO-treated mice was significantly $(p<0.05)$ lower than that found in cells from control mice at all experimental time points (Figure 1A). An increase in basal $\mathrm{Ca}^{2+}$ levels may indicate that the cells are not capable of storing $\mathrm{Ca}^{2+}$ in intracellular stores. Accordingly (Figure 1B), delta increase in $\left[\mathrm{Ca}^{2+}\right]_{i}$ induced by thapsigargin, an endoplasmatic reticulum $\mathrm{Ca}^{2+}$ stores depletor, in cardiomyocytes from DOXO-treated mice was significantly lower $(p<0.001)$ than that registered in cardiomyocytes from control mice, even in presence of a single DOXO administration, which may indicate a reduced $\mathrm{Ca}^{2+}$ storage in the endoplasmic reticulum. In the same way, the delta increase in $\left[\mathrm{Ca}^{2+}\right]_{\mathrm{i}}$ induced by FCCP, a mitochondrial $\mathrm{Ca}^{2+}$ depletory, in cardiomyocytes from DOXO-treated mice was significantly $(p<0.001)$ lower than that found in cells from control mice in all experimental groups (Figure 1C), suggestive of less build-up of $\mathrm{Ca}^{2+}$ also in the mitochondria.
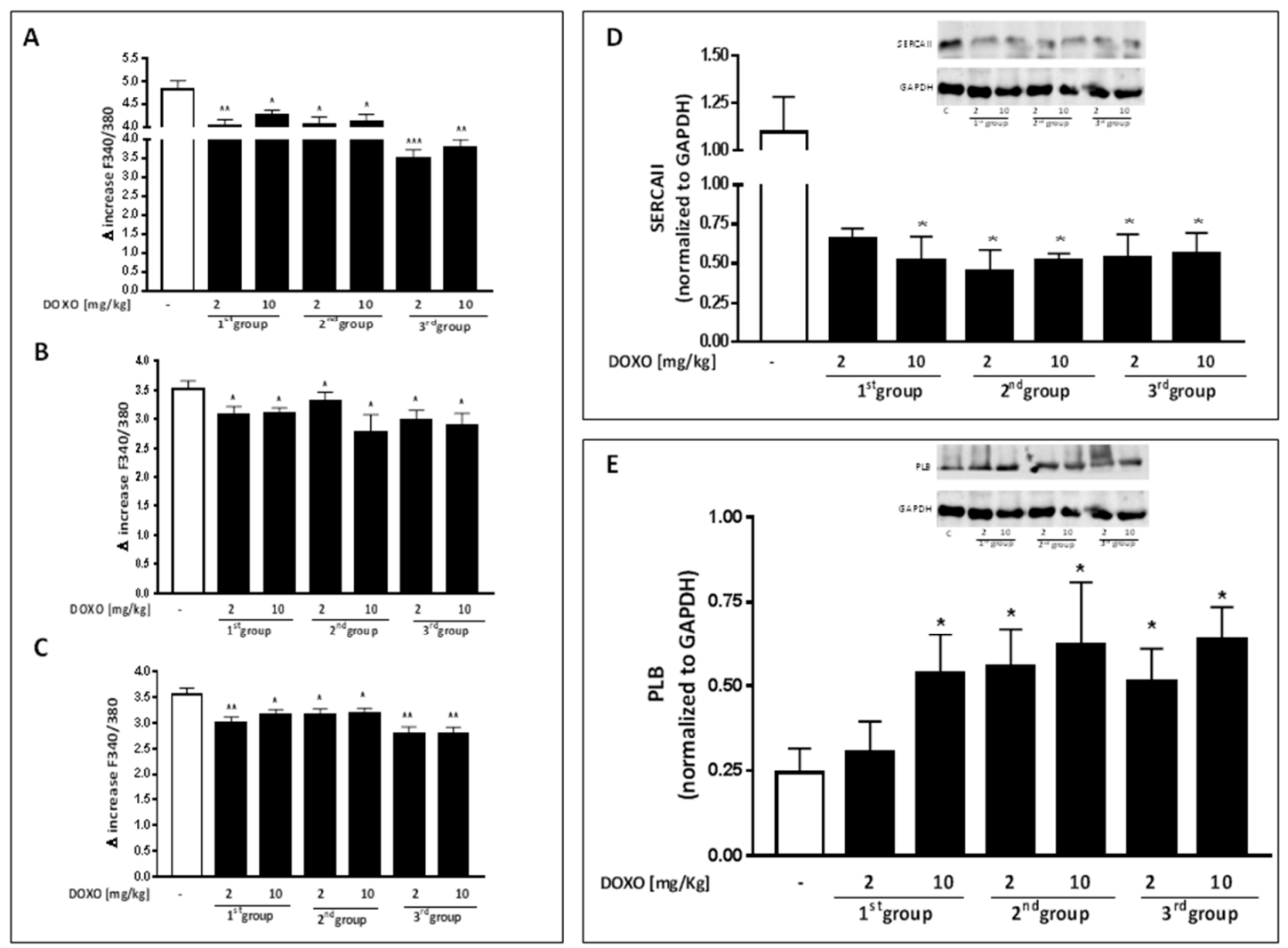

Figure 1. Effect of DOXO on calcium homeostasis. Mice received a single administration (1th group), two administrations (2nd group) or three administrations (3rd group) of DOXO (2 or $10 \mathrm{mg} / \mathrm{kg}$; i.p.) and primary cardiomyocytes were isolated by enzymatic digestion. Intracellular calcium content in cells suspension was evaluated by using ionomycin $(1 \mu \mathrm{M})(\mathbf{A})$; reticulum calcium content was evaluated by means of thapsygargin $(100 \mathrm{nM})(\mathbf{B})$ and mitochondrial calcium content was evaluated by using FCCP $(50 \mathrm{nM})(\mathrm{C})$. Results were expressed as mean \pm S.E.M. of delta $(\delta)$ increase of FURA-2 AM ratio fluorescence $(340 / 380 \mathrm{~nm})$ from at least three independent experiments each performed in duplicate. Data were analyzed by Student's $t$-test. ${ }^{*} p<0.05,{ }^{* *} p<0.005$ and ${ }^{* * *} p<0.001$ vs. control. Effect of DOXO on SERCA II (D) and PLB (E) expression. Mice received a single administration (first group), two administrations (second group), or three administrations (third group) of DOXO ( $2 \mathrm{mg} / \mathrm{kg}$ or $10 \mathrm{mg} / \mathrm{kg}$; i.p.) and SERCA II and PLB expressions were detected by Western blot analysis into tissue homogenates from mice; GAPDH protein expression was used as loading control. Values were expressed as mean \pm S.E.M. from at least three independent experiments each performed in duplicate. Data were analyzed by Student's $t$-test. * $p<0.05$ vs. control. 
Among all regulatory mechanisms involved in intracellular $\mathrm{Ca}^{2+}$ homeostasis, SERCAII plays a pivotal role. Many studies report how changes in the expression and/or activity of SERCAII, regulated by phospholamban (PLB), are altered in many forms of cardiomyopathy [31]. Therefore, we analyzed the expression levels of SERCAII and PLB and $\mathrm{Ca}^{2+}$ levels in the heart of DOXO-treated mice. Data obtained by Western blot analysis showed a significant $(p<0.05)$ reduction of SERCAII expression always in mice that received a single DOXO administration (Figure 1D) and a concomitant increase in PLB expression (Figure 1E).

\subsection{Doxorubicin Administration Affects Cx43 Expression and Localization}

Besides alterations in $\mathrm{Ca}^{2+}$ homeostasis, several forms of cardiomyopathy, such as hypertrophy, and dilated and ischemic cardiomyopathy are also characterized by abnormal Cx43 expression and distribution in the heart [32]. As depicted in Figure 2A, DOXO-treatment induces a decrease of total $\mathrm{C} \times 43$ also evident in mice that received a single dose of DOXO.
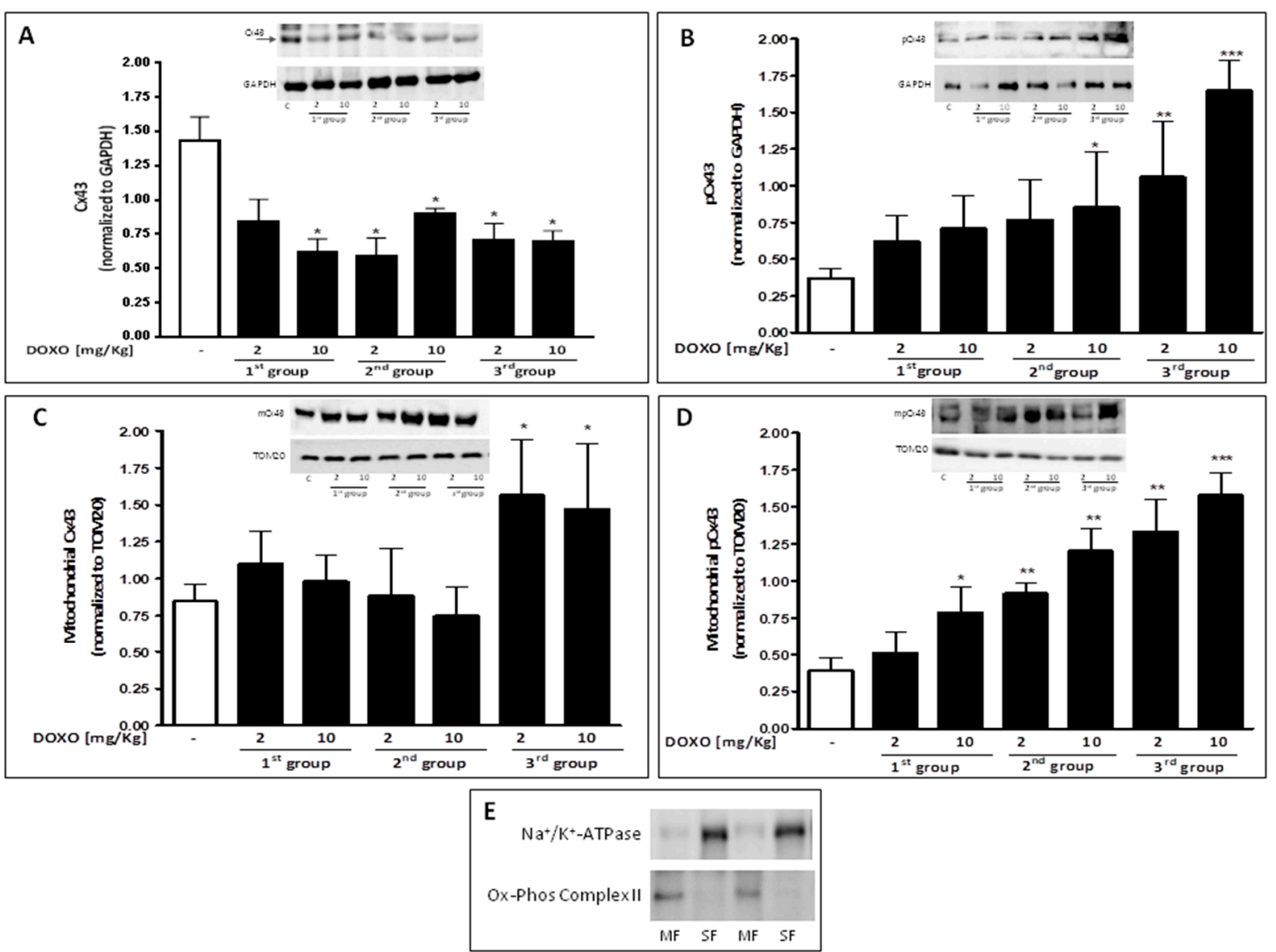

Figure 2. Mice received a single administration (first group), two administrations (second group), or three administrations (third group) of DOXO (2 mg/ $\mathrm{kg}$ and $10 \mathrm{mg} / \mathrm{kg}$; i.p.) and Cx43 and pCx43 expressions were detected by Western blot analysis into tissue homogenates from mice; GAPDH protein expression was used as loading control (A,B); Effects of DOXO on mCx43 (C) and mpCx43 (D) expression were detected by Western blot analysis on mitochondrial protein lysate from mice; TOM20 protein expression was used as loading control. Values were expressed as mean \pm S.E.M. from at least three independent experiments each performed in duplicate. Values are expressed as mean \pm S.E.M. from at least three independent experiments each performed in duplicate. Data were analyzed by Student's $t$-test. ${ }^{*} p<0.05,{ }^{* *} p<0.005$ and ${ }^{* * *} p<0.001$ versus control. Representative Western blots of $\mathrm{Na}^{+} / \mathrm{K}^{+}$ATPase and Ox-Phos Complex II were used as markers of sarcolemma (SF) and mitochondria $(\mathrm{MF})$, respectively, to demonstrate the purity of the mitochondrial extracts (E). 
Western blot analysis performed on heart lysates of treated-mice confirmed that, compared to control mice, DOXO-treated mice had a significant $(p<0.05)$ reduction of $\mathrm{Cx} 43$ expression, that could be observed in all experimental groups (Figure 2A). Phosphorylation of Cx43 affects its main biological properties [33]. In particular, phosphorylation on Ser368 is linked to metabolic and/or electrical uncoupling of gap junctions [34] and induces channels closure [35]. Accordingly, Western blot analysis showed a significant $(p<0.05)$ increase in Cx43 phosphorylated on Ser368 in DOXO-treated mice (Figure 2B).

In addition to the function performed at gap junction levels, it has recently been shown that Cx43 is also expressed at mitochondrial level, where it is involved in cardioprotection [36,37]. Mitochondrial Cx43 levels increase in stress conditions such as ischemia-reperfusion [27] or DOXO-induced cardiotoxicity [17]. Western blot analysis on mitochondrial lysates from hearts of DOXO-treated mice confirmed that $\mathrm{Cx} 43$ expression on mitochondria significantly $(p<0.05)$ increases with the treatment duration in DOXO-treated mice (Figure 2C). Mitochondrial expression of Cx43 phosphorylated on Ser368 significantly $(p<0.005)$ increased in a time dependent-manner in the heart of DOXO-treated mice (Figure 2D). Immunofluorescence analysis performed on heart sections double-stained for Cx43 and TOM20, as a marker of mitochondria, confirmed an increased mitochondrial localization of Cx43 in the heart of DOXO-treated mice (Figure 3).

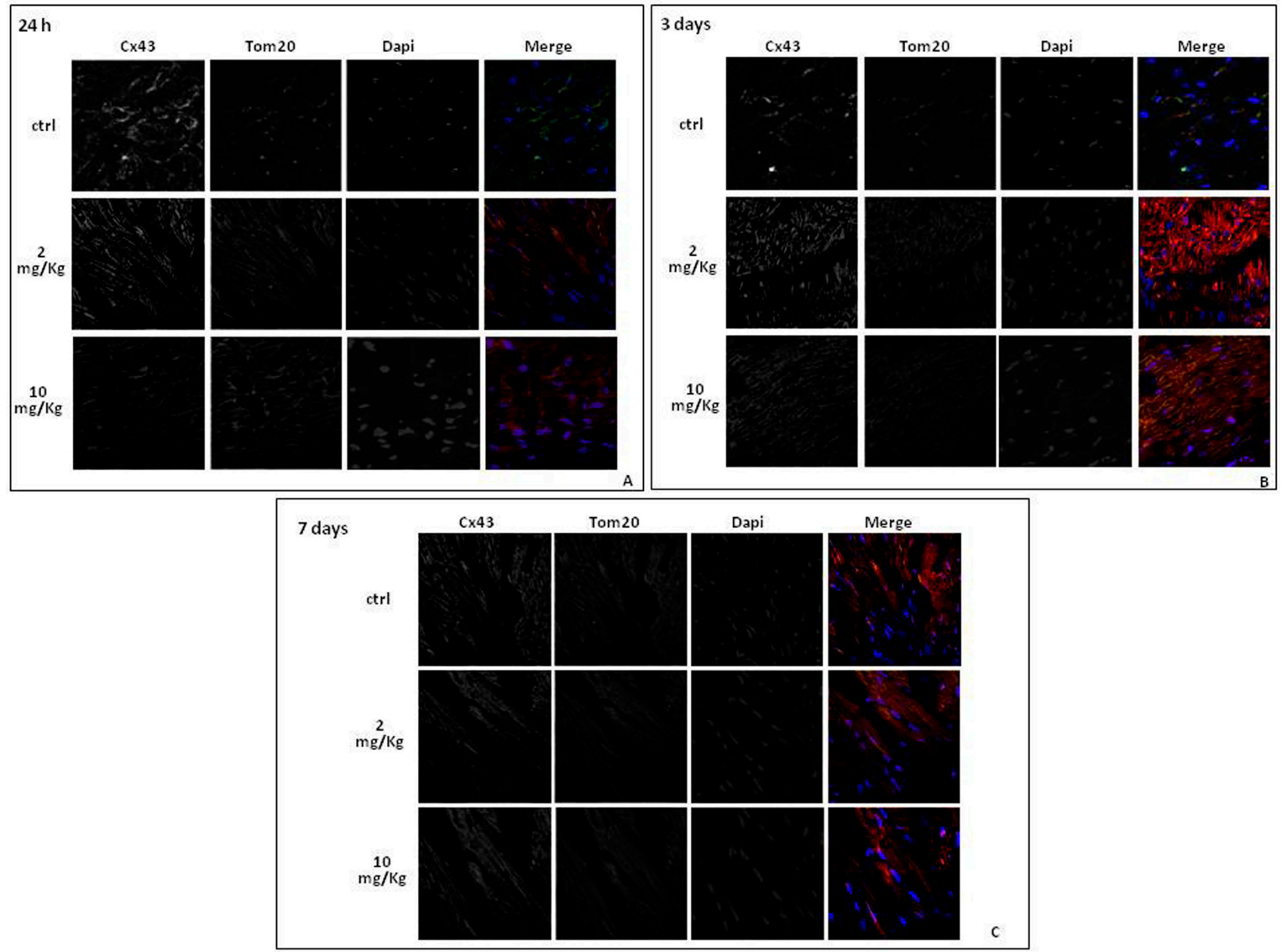

Figure 3. Effect of DOXO (2 and $10 \mathrm{mg} / \mathrm{kg}$; i.p.) on Cx43 localization in heart of C57BL/6j mice which received a single administration (first group), two administrations (second group), or three administrations (third group). Frozen myocardial tissue sections were stained with Anti-Cx43 (green), TOM20 (red) and nucleus with DAPI (blue) and were determined by Immunofluorescence assay at confocal microscopy for mitochondrial Cx43 localization. Scale bar $10 \mu \mathrm{m}$. 


\section{Discussion}

The anthracycline anticancer drug DOXO is a cornerstone in many malignancies. However, its clinical use is hindered by high risk of cardiotoxicity [38]. Much is known about the long-term toxicity of DOXO, but just as important appear to be its short-term effects [8,39]. DOXO-induced acute cardiotoxicity occurs in about $11 \%$ of patients in which the onset of paroxysmal non sustained supraventricular tachycardia and premature atrial and ventricular beats are observed [4]. The mechanisms underlying DOXO cardiotoxicity are not fully understood, but a large body of evidence indicates that anthracyclines interfere with calcium homeostasis, that is largely involved both in cardiac dysfunction and in apoptosis, the two major signs of DOXO-induced cardiotoxicity. In view of the pivotal role played by $\mathrm{Cx} 43$ in cardiac function and in cell death signal propagation, this study aimed to analyze the effect of DOXO administration on Cx43 expression and localization in a short-term model of DOXO-induced cardiotoxicity in mice developed by our group and previously published [8]. Doses of Doxo administered are 2 and $10 \mathrm{mg} / \mathrm{kg}$ and are the lowest doses reported in the literature $[40,41]$.

It is worth noting that the used doses, although lower than those used in humans or in other animal studies, are able to induce clear signs of cardiac dysfunction, such as decreased EF and FS and increased LVESD, and are even evident in mice that received a single administration of DOXO. It is well known that systolic and diastolic function of the heart are regulated by calcium handling [42]. In our experimental model, we observed a significant dysfunction in $\mathrm{Ca}^{2+}$ homeostasis in DOXO-treated mice. Indeed, as confirmed by means of Fura-2 pentakis(acetoxymethyl) ester (FURA-2AM), endoplasmic reticulum $\mathrm{Ca}^{2+}$ content from cardiomyocytes isolated from DOXO-treated mice was significantly lower than that of control mice at all experimental times. In line with earlier reports [31], Western blot analysis showed a significant decrease of SERCAII expression in the heart of DOXO-treated mice, confirming the central role of SERCAII in maintaining intracellular calcium homeostasis in the heart [42]. Moreover, our results showed a significant increased expression of PLB, a protein expressed in the sarcoplasmic reticulum membrane with inhibitory effects on SERCAII, in DOXO-treated mice, with a further alteration of cytosolic $\mathrm{Ca}^{2+}$ content. Previous studies suggest a functional role of the gap junction/intercellular communication in the regulation of $\mathrm{Ca}^{2+}$ signalling in diseased heart $[43,44]$, which may explain, at least in part, our findings on intracellular $\mathrm{Ca}^{2+}$ regulation. Abnormal expression of Cx43, the main gap junction's protein in the heart, has been reported in several forms of cardiomyopathies: i.e., hypertrophic, dilated, and ischemic cardiomyopathy. Furthermore, recently alterations in Cx43 expression and localization have been proved in DOXO-treated cardiomyoblast cell line [17]. Our data demonstrate that, as in other forms of cardiomyopathies, in our experimental model of DOXO-induced acute cardiomyopathy, Cx43 expression was significantly reduced.

Downregulation and heterogeneous redistribution of Cx43 in diseased heart has been reported [32]. In this study we demonstrated that in addition to reducing expression of Cx43, DOXO significantly increases the expression of Cx43 phosporylated on Ser368. PKC-mediate phosphorylation on Ser affects the metabolic and electrical conduction through the gap junction. Specifically, phosphorylation on Ser368 creates a 'closed', conformational state, with a consequent electrical and chemical uncoupling. Furthermore, phosphorylation on Ser368 blocks the access of other kinases and phosphatases to the C-terminal residue [45]. It has been reported that interruption of cell-to-cell communication through gap junctions is a mechanism of defense implemented by cells to block the propagation of harmful stimuli. This event takes the name of "good Samaritan" effect [46] even if this involves alterations in the propagation of electrical impulses. So we can hypothesize that the reduced expression of Cx43 and the concomitant increase of Cx43 phosphorylated on Ser368 in the heart of DOXO-treated mice is a mechanism put in place to try to defend the cardiomyocytes from the propagation of harmful stimuli, such as calcium overload, although this involves alterations in cardiac functions such as those observed with echocardiography in our experimental model. 
Intracellular $\mathrm{Ca}^{2+}$ homeostasis is fine-tuned by the cyclical uptake and release by the different cellular compartments [47]. Recent evidence points to a role of Cx43 in mitochondrial homeostasis of $\mathrm{Ca}^{2+}[48,49]$.

The increase of $\mathrm{mCx} 43$ in cardiomyocytes can be induced by various stimuli, such as cellular stress and ischemic preconditioning, but its functional relevance is still unclear. It has been postulated that $\mathrm{mCx} 43$ is part of multiprotein complex that somehow controls mitochondrial homeostasis and that it forms hemichannels that serve as a conduit for ion flux [50], like $\mathrm{Ca}^{2+}$. Interaction between proteins involved in this multiprotein complex is reinforced by PKC that mediates phosphorylation of the Cx43 at Ser368 residue [51]. In our experimental model, we found a significant increase of $\mathrm{mCx} 43$ and of $\mathrm{mCx} 43$ phosporylated on Ser368 expression. $\mathrm{mCx} 43$ protects cardiomyocytes by mitigating $\mathrm{Ca}^{2+}$ overload, mitochondrial permeability transition, and cell death [47]. In agreement with this hypothesis, our data show that increased $\mathrm{mCx} 43$ and $\mathrm{mCx} 43$ phosphorylated on Ser368 expression is associated with a reduced accumulation of $\mathrm{Ca}^{2+}$ in the mitochondria.

\section{Materials and Methods}

\subsection{Materials}

DOXO was purchased from Baxter manufacturing S.p.a. (Officina di Sesto Fiorentino, Florence, Italy). Where not indicated otherwise, antibodies used were purchased from Santa Cruz Biotechnology (DBA, Milan, Italy), and all other products were purchased from Sigma (Milan, Italy).

\subsection{Animals}

Six week old female C57BL/6j (weighting 20-22 g) were purchased from Charles River (Lecco, Italy). All experimental procedures that involve animals have been conducted in agreement with the Italian and European Community Council for Animal Care (DL. no. 26/2014 protocol number of Ministerial approvation DGSAF 13788-A 02/07/2015) and in accordance with the guidelines of the Guide for the Care and Use of Laboratory Animals of the National Institutes of Health.

\subsection{Experimental Protocols}

This study was performed using a previously well-established animal model of short-term DOXO induced cardiotoxicity [8]. Briefly, C57BL/6j mice were randomly divided in three groups $(n=6$ for each experimental group). The doses used were 2 and $10 \mathrm{mg} / \mathrm{kg}[40,41]$ and they corresponded to 6.142 and $30.8 \mathrm{mg} / \mathrm{m}^{2}$ respectively [52].

First Group: received one DOXO administration (2 or $10 \mathrm{mg} / \mathrm{kg}$ i.p.) and were sacrificed $24 \mathrm{~h}$ after the treatment;

Second Group: received two DOXO administrations ( 2 or $10 \mathrm{mg} / \mathrm{kg}$ i.p.) once a day for two days and were sacrificed three days after the first administration;

Third Group: received three DOXO administrations ( 2 or $10 \mathrm{mg} / \mathrm{kg}$ i.p.) once a day for three days and were sacrificed seven days after the first administration.

Mice that received saline were used as control group. Cardiac function was monitored echocardiographically at baseline and before sacrifice. At the end of each experimental time, heart samples were collected and prepared for molecular biological analyses.

\subsection{Echocardiogram}

Mice were lightly anesthetized with $1-1.5 \%$ of isoflurane in oxygen until the heart rate stabilized to 400-500 beats per minute. Echocardiography was performed using VEVO (VisualSonic, Toronto, ON, Canada) instrument. Ejection fraction (EF), Fractional shortening (FS), Left Ventricular End-Diastolic-Diameter (LVEDD), and Left Ventricular End-Systolic Diameter (LVESD) were calculated using the VEVO analysis software. 


\subsection{Protein Extraction and Western Blot Analysis}

Total proteins were extracted by homogenization of hearts with a dounce potter in lysis buffer (TRIS-HCl $50 \mathrm{mM}, \mathrm{NaCl} 500 \mathrm{mM}$, protease inhibitors, PMSF $0.25 \mu \mathrm{M}, \mathrm{NaF} 50 \mathrm{mM}, \mathrm{Na}_{3} \mathrm{VO}_{4}$ $0.2 \mathrm{mM}$ ). Protein concentrations were determined with the Bio-Rad protein assay (BIO-RAD, Milan, Italy). Equal amounts of protein $(50 \mu \mathrm{g})$ were loaded into an acrylamide gel and separated by SDS-PAGE under denaturating conditions. Blots were incubated with primary antibody anti-Cx43 (Sigma C6219), anti-pCx43 phosphorylate on Ser368 (pCx43; Santa Cruz, Dallas, TX, USA, SC-17219-R), anti-sarco/endoplasmic reticulum Ca ${ }^{2+}$-ATPase (SERCAII; Santa Cruz: SC-376235), anti-phospholamban (PLB; Santa Cruz: SC-21923), or anti-glyceraldehyde 3-phosphate dehydrogenase (GAPDH; Santa Cruz: 32233) (used as loading control) overnight at $4{ }^{\circ} \mathrm{C}$. After incubation period with the primary antibodies, blots were washed in PBS $0.1 \%$ Tween. The appropriate secondary antibody - anti-rabbit, anti-mouse, or anti-goat (each diluted 1:4000)—was added and allowed in incubation for $1 \mathrm{~h}$ at room temperature. Immunoreactive protein bands were detected by chemiluminescence using enhanced chemiluminescence reagents (ECL) in LAS 4000 (GE Healthcare, (Björkgatan, Uppsala, Sweden).

\subsection{Mitochondrial Protein Extraction and Western Blot Analysis for Mitochondrial Cx43 and $p C x 43$}

Mitochondrial proteins were extracted from homogenized hearts with a dounce potter in lysis buffer (sucrose $250 \mathrm{mM}, \mathrm{K}^{+}$Hepes pH $7.520 \mathrm{mM}, \mathrm{KCl} 10 \mathrm{mM}, \mathrm{MgCl}_{2} 1.5 \mathrm{mM}$, EDTA $0.1 \mathrm{mM}$, EGTA $1 \mathrm{mM}$, protease inhibitors, $\mathrm{NaF} 50 \mathrm{mM}, \mathrm{Na}_{3} \mathrm{VO}_{4} 0.2 \mathrm{mM}$, PMSF $100 \mu \mathrm{M}$, DTT $1 \mathrm{mM}$, digitonin $0.025 \%$ ) as previously reported $[17,53,54]$. The protein yield was quantified with the Bio-Rad protein assay (BIO-RAD, Milan, Italy). Western blot analysis for $\mathrm{Cx} 43$ or $\mathrm{pCx} 43$ was performed as described above. Primary antibody anti-TOM20 (Santa Cruz: SC-11415) was used as loading control. In order to verify the purity of mitochondrial protein extraction, a Western blot analysis was performed to evaluate the presence of proteins expressed only in the mitochondria (ox-Phos Complex II, Abcam, Cambridge, UK: ab14715) and the absence of proteins expressed in other cellular compartments $\left(\mathrm{Na}^{+} / \mathrm{K}^{+}\right.$ATPase, Abcam: ab7671) [55].

\subsection{Primary Cardiomyocytes Isolation and Measurement of Intracellular $\mathrm{Ca}^{2+}$ Signaling}

Intracellular $\mathrm{Ca}^{2+}$ concentrations were measured in primary cardiomyocytes, isolated from hearts of DOXO-treated mice and control mice. Hearts were washed with HBSS $0.1 \mathrm{mM} \mathrm{Ca}^{2+}(140 \mathrm{mM} \mathrm{NaCl}$, $5.4 \mathrm{mM} \mathrm{KCl}, 0.44 \mathrm{mM} \mathrm{KH}_{2} \mathrm{PO}_{4}, 0.42 \mathrm{mM} \mathrm{Na}_{2} \mathrm{H} \mathrm{PO}_{4}, 4.17 \mathrm{mM} \mathrm{NaHCO}_{3}, 26 \mathrm{mM}$ CaNa-EDTA, $0.10 \mathrm{mM}$ $\mathrm{CaCl}_{2} \cdot \mathrm{H}_{2} \mathrm{O}, 5.0 \mathrm{mM}$ HEPES and $5.5 \mathrm{mM}$ dextrose). Next, hearts were cut in 1-2 mm sections and incubated at $37^{\circ} \mathrm{C}$ in HBSS $0.1 \mathrm{mM} \mathrm{Ca}^{2+}$ containing albumin $10 \mathrm{mg} / \mathrm{mL}$, tryspin inhibitor $1 \mathrm{mg} / \mathrm{mL}$, taurine $5 \mathrm{mM}$, dithiothreitol $0.4 \mathrm{mg} / \mathrm{mL}$, collagenase II $0.6 \mathrm{mg} / \mathrm{mL}$, and papain $0.6 \mathrm{mg} / \mathrm{mL}$ for $75 \mathrm{~min}$. After the incubation period, tissue fragments were removed by filtering the suspension with a $0.70 \mu$ filter. Filtrate was centrifuged to collect the cardiomyocytes. Primary cardiomyocytes were loaded with the ratiometric fluorescent indicator dye FURA2-AM $\left(5 \mu \mathrm{M}, 45 \mathrm{~min}, 37^{\circ} \mathrm{C}\right)$ at a cell density of $3 \times 10^{4}$ cells $/ \mathrm{mL}$ in HBSS $0.1 \mathrm{mM} \mathrm{Ca}^{2+}$. FURA2-AM excess was removed by washing the cells with HBSS and cardiomyocytes were then transferred to a spectrofluorimeter (Perkin-Elmer LS-50, Waltham, MA, USA). As reported for FURA2-AM, the excitation wavelength was alternated between 340 and $380 \mathrm{~nm}$, and the emission wavelength was $515 \mathrm{~nm}$. The basal F340/F380 ratio was recorded and then treatment with ionomycin $(1 \mu \mathrm{M})$, a calcium ionophore; thapsigargin $(1 \mu \mathrm{M})$, an inhibitor of sarco (endo) plasmic reticulum; or carbonyl cyanide p-trifluoromethoxypyhenylhydrazone (FCCP; $50 \mathrm{nM}$ ), a mitochondrial calcium depletory, was added into the cuvette in $\mathrm{Ca}^{2+}$-free HBSS and F340/F380 ratio was recorded $5 \mathrm{~min}$ after each stimulus induced. The ratio of fluorescence intensity of $340 / 380 \mathrm{~nm}$ (F340/F380) is strictly related to intracellular free $\left[\mathrm{Ca}^{2+}\right]$ [56]. Results are expressed as delta increase of F340/F380, calculated as F340/F380 stimulus-F340/F380 basal. 


\subsection{Immunohistochemical Analysis}

For immunohistochemical analyses, frozen cardiac tissues were embedded in OCT compound (Bio-Optica, Milan, Italy). Sections $(7 \mu \mathrm{m})$ were incubated with mouse anti-Cx43 and rabbit anti-TOM20 for $2 \mathrm{~h}$ at room temperature. Then the slides were washed three times with PBS and incubated with secondary antibodies (FITC-conjugated anti mouse IgG and Texas red-conjugated anti rabbit IgG) for $1 \mathrm{~h}$. DAPI was used to mark the nuclei. After mounting, coverslips were examined by using a Laser Confocal Microscope (Leica TCS SP5, Wetzlar, Germany).

\subsection{Statistical Analysis}

Data are reported as the mean \pm standard error mean (S.E.M.) of at least three independent experiments. Statistical differences were assessed with Student's $t$-test. $p$-values of less than 0.05 was considered significant.

\section{Conclusions}

In this work, we have shown that even a short-term administration of DOXO is able to induce significant changes in calcium homeostasis and alterations in Cx43 expression and localization. These effects are evident even in hearts of mice that received a single DOXO-administration, but such a rapid response is not surprising. Indeed, each DOXO administration can induce structural changes in cardiomyocytes that ultimately lead to death of cardiomyocytes themselves. These alterations may be somewhat balanced by the establishment of compensatory mechanisms until a certain threshold, above which cardiac injury is triggered [57].

Acknowledgments: This work was supported by a grant from the University of Salerno (FARB 2014).

Author Contributions: Michela Pecoraro and Ada Popolo conceived and designed the experiments; Michela Pecoraro, Stefania Marzocco and Michele Ciccarelli performed the experiments; Antonio Rodríguez-Sinovas, Ada Popolo, Guido Iaccarino and Aldo Pinto analyzed the data; Ada Popolo, Michela Pecoraro and Aldo Pinto wrote the paper.

Conflicts of Interest: The authors declare no conflict of interest.

\section{References}

1. Wallace, K.B. Doxorubicin-induced cardiac mitochondrionopathy. Pharmacol. Toxicol. 2003, 93, $105-115$. [CrossRef] [PubMed]

2. Ferrans, V.J.; Clark, J.R.; Zhang, J.; Yu, Z.X.; Herman, E.H. Pathogenesis and prevention of doxorubicin cardiomyopathy. Tsitologiya 1997, 39, 928-936.

3. Medrano, F.L.; Munoz, A.S.; Sánchez, V.S.; Pérez-Herrero, J.R.C. Cardiotoxicity of 5 fluorouracil: Ischemia or myocardial toxicity? Rev. Clin. Esp. 2001, 201, 106-107.

4. Chatterjee, K.; Zhang, J.; Honbo, N.; Karliner, J.S. Doxorubicin Cardiomyopathy. Cardiology 2010, 115, 155-162. [CrossRef] [PubMed]

5. Takemura, G.; Fujiwara, H. Doxorubicin-induced cardiomyopathy from the cardiotoxic mechanisms to management. Prog. Cardiovasc. Dis. 2007, 49, 330-352. [CrossRef] [PubMed]

6. Angsutararux, P.; Luanpitpong, S.; Issaragrisil, S. Chemotherapy-Induced Cardiotoxicity: Overview of the Roles of Oxidative Stress. Oxid. Med. Cell Longev. 2015, 2015, 795602. [CrossRef] [PubMed]

7. Menna, P.; Salvatorelli, E.; Minotti, G. Cardiotoxicity of antitumor drugs. Chem. Res. Toxicol. 2008, 21, 978-989. [CrossRef] [PubMed]

8. Pecoraro, M.; Del Pizzo, M.; Marzocco, S.; Sorrentino, R.; Ciccarelli, M.; Iaccarino, G.; Pinto, A.; Popolo, A. Inflammatory mediators in a short-time mouse model of doxorubicin-induced cardiotoxicity. Toxicol. Appl. Pharmacol. 2016, 293, 44-52. [CrossRef] [PubMed]

9. Octavia, Y.; Tocchetti, C.G.; Gabrielson, K.L.; Janssens, S.; Crijns, H.J.; Moens, A.L. Doxorubicin-induced cardiomyopathy: From molecular mechanisms to therapeutic strategies. J. Mol. Cell. Cardiol. 2012, 52, 1213-1225. [CrossRef] [PubMed] 
10. Yu, Q.; Li, Q.; Na, R.; Li, X.; Liu, B.; Meng, L.; Liutong, H.; Fang, W.; Zhu, N.; Zheng, X. Impact of repeated intravenous bone marrow mesenchymal stem cells infusion on myocardial collagen network remodeling in a rat model of doxorubicin-induced dilated cardiomyopathy. Mol. Cell. Biochem. 2014, 387, 279-285. [CrossRef] [PubMed]

11. Berthiaume, J.M.; Wallace, K.B. Adriamycin-induced oxidative mitochondrial cardiotoxicity. Cell. Biol. Toxicol. 2007, 23, 15-25. [CrossRef] [PubMed]

12. Horenstein, M.S.; Vander Heide, R.S.; L'Ecuyer, T.J. Molecular basis of anthracycline-induced cardiotoxicity and its prevention. Mol. Genet. Metab. 2000, 71, 436-444. [CrossRef] [PubMed]

13. Zhang, Y.; Chen, Y.; Zhang, M.; Tang, Y.; Xie, Y.; Huang, X.; Li, Y. Doxorubicin induces sarcoplasmic reticulum calcium regulation dysfunction via the decrease of SERCA2 and phospholamban expressions in rats. Cell Biochem. Biophys. 2014, 70, 1791-1798. [CrossRef] [PubMed]

14. O'Connell, J.L.; Romano, M.M.; Campos Pulici, E.C.; Carvalho, E.E.; de Souza, F.R.; Tanaka, D.M.; Maciel, B.C.; Salgado, H.C.; Fazan-Júnior, R.; Rossi, M.A.; et al. Short-term and long-term models of doxorubicin-induced cardiomyopathy in rats: A comparison of functional and histopathological changes. Exp. Toxicol. Pathol. 2017, 69, 213-219. [CrossRef] [PubMed]

15. Ma, Y.; Yang, L.; Ma, J.; Lu, L.; Wang, X.; Ren, J.; Yang, J. Rutin attenuates doxorubicin-induced cardiotoxicity via regulating autophagy and apoptosis. Biochim. Biophys. Acta 2017, 1863, 1904-1911. [CrossRef] [PubMed]

16. Robert, J. Long-term and short-term models for studying anthracycline cardiotoxicity and protectors. Cardiovasc. Toxicol. 2007, 7, 135-139. [CrossRef] [PubMed]

17. Pecoraro, M.; Sorrentino, R.; Franceschelli, S.; Del Pizzo, M.; Pinto, A.; Popolo, A. Doxorubicin-Mediated Cardiotoxicity: Role of Mitochondrial Connexin 43. Cardiovasc. Toxicol. 2015, 15, 366-376. [CrossRef] [PubMed]

18. He, H.; Li, N.; Zhao, Z.; Han, F.; Wang, X.; Zeng, Y. Ischemic postconditioning improves the expression of cellular membrane connexin 43 and attenuates the reperfusion injury in rat acute myocardial infarction. Biomed. Rep. 2015, 3, 668-674. [CrossRef] [PubMed]

19. Severs, N.J.; Bruce, A.F.; Dupont, E.; Rothery, S. Remodelling of gap junctions and connexion expression in diseased myocardium. Cardiovasc. Res. 2008, 80, 9-19. [CrossRef] [PubMed]

20. Allen, A. The cardiotoxicity of chemotherapeutic drugs. Semin. Oncol. 1992, 19, 529-542. [PubMed]

21. Maron, B.J. Hypertrophic cardiomyopathy: A systematic review. JAMA 2002, 287, 1308-1320. [CrossRef] [PubMed]

22. Johansen, D.; Cruciani, V.; Sundset, R.; Ytrehus, K.; Mikalsen, S.O. Ischemia induces closure of gap junctional channels and opening of hemichannels in heart-derived cells and tissue. Cell. Physiol. Biochem. 2011, 28, 103-114. [CrossRef] [PubMed]

23. Salas, D.; Puebla, C.; Lampe, P.D.; Lavandero, S.; Sáez, J.C. Role of Akt and $\mathrm{Ca}^{2+}$ on cell permeabilization via connexin43 hemichannels induced by metabolic inhibition. Biochim. Biophys. Acta 2015, 1852, 1268-1277. [CrossRef] [PubMed]

24. Popolo, A.; Morello, S.; Sorrentino, R.; Pinto, A. Antiadrenergic effect of adenosine involves connexin 43 turn-over in H9c2 cells. Eur. J. Pharmacol. 2013, 715, 56-61. [CrossRef] [PubMed]

25. Spray, D.C.; Burt, J.M. Structure-activity relations of the cardiac gap junction channel. Am. J. Physiol. 1990, 258, 195-205.

26. Alex, J.; Cale, A.R.J.; Griffin, S.C.; Cowen, M.E.; Guvendik, L. Connexins: The basis of functional coupling of myocyte. J. Clin. Basic Cardiol. 2005, 8, 19-22.

27. Rodriguez-Sinovas, A.; Boengler, K.; Cabestrero, A.; Gres, P.; Morente, M.; Ruiz-Meana, M.; Konietzka, I.; Miró, E.; Totzeck, A.; Heusch, G.; et al. Translocation of connexin43 to the inner mitochondrial membrane of cardiomyocytes through the heat shock protein90-dependent TOM pathway and its importance for cardioprotection. Circ. Res. 2006, 99, 93-101. [CrossRef] [PubMed]

28. Thimm, J.; Mechler, A.; Lin, H.; Rhee, S.; Lal, R. Calcium-dependent open/closed conformations and interfacial energy maps of reconstituted hemichannels. J. Biol. Chem. 2005, 280, 10646-10654. [CrossRef] [PubMed]

29. Bol, M.; Wang, N.; De Bock, M.; Wacquier, B.; Decrock, E.; Gadicherla, A.; Decaluwé, K.; Vanheel, B.; van Rijen, H.V.; Krysko, D.V.; et al. At the cross-point of connexins, calcium, and ATP: Blocking hemichannels inhibits vasoconstriction of rat small mesenteric arteries. Cardiovasc. Res. 2017, 113, 195-206. [CrossRef] [PubMed] 
30. Oyamada, M.; Tsujii, E.; Tanaka, H.; Matsushita, T.; Takamatsu, T. Abnormalities in gap junctions and Ca ${ }^{2+}$ dynamics in cardiomyocytes at the border zone of myocardial infarcts. Cell Commun. Adhes. 2001, 8, 335-338. [CrossRef] [PubMed]

31. Periasamy, M.; Bhupathy, P.; Babu, G.J. Regulation of sarcoplasmic reticulum Ca ${ }^{2+}$ ATPase pump expression and its relevance to cardiac muscle physiology and pathology. Cardiovasc. Res. 2008, 77, 265-273. [CrossRef] [PubMed]

32. Fontes, M.S.; vanVeen, T.A.; deBakker, J.M.; vanRijen, H.V. Functional consequences of abnormal Cx43 expression in the heart. Biochim. Biophys. Acta 2012, 1818, 2020-2029. [CrossRef] [PubMed]

33. Jeyaraman, M.M.; Srisakuldee, W.; Nickel, B.E.; Kardami, E. Connexin43 phosphorylation and cytoprotection in the heart. Biochim. Biophys. Acta 2012, 1818, 2009-2013. [CrossRef] [PubMed]

34. Solan, J.L.; Lampe, P.D. Connexin43 phosphorylation: Structural changes and biological effects. Biochem. J. 2009, 419, 261-272. [CrossRef] [PubMed]

35. Boengler, K.; Schulz, R.; Heusch, G. Connexin43 signalling and cardioprotection. Heart 2006, 92, $1724-1727$. [CrossRef] [PubMed]

36. Sakurai, T.; Tsuchida, M.; Lampe, P.D.; Murakami, M. Cardiomyocyte FGF signaling is required for Cx43 phosphorylation and cardiac gap junction maintenance. Exp. Cell Res. 2013, 319, 2152-2165. [CrossRef] [PubMed]

37. Kalvelyte, A.; Imbrasaite, A.; Bukauskiene, A.; Verselis, V.K.; Bukauskas, F.F. Connexins and apoptotic transformation. Biochem. Pharmacol. 2003, 66, 1661-1672. [CrossRef]

38. Ascensão, A.; Oliveira, P.J.; Magalhães, J. Exercise as a beneficial adjunct therapy during Doxorubicin treatment-Role of mitochondria in cardioprotection. Int. J. Cardiol. 2012, 156, 4-10. [CrossRef] [PubMed]

39. Mercuro, G.; Cadeddu, C.; Piras, A.; Dessì, M.; Madeddu, C.; Deidda, M.; Serpe, R.; Massa, E.; Mantovani, G. Early epirubicin-induced myocardial dysfunction revealed by serial tissue Doppler echocardiography: Correlation with inflammatory and oxidative stress markers. Oncologist 2007, 12, 1124-1133. [CrossRef] [PubMed]

40. Xujie, L.; Xinggang, W.; Xian, Z.; Yeqing, X.; Ruizhen, C.; Haozhu, C. C57BL/6 Mice are More Appropriate than BALB/C Mice in Inducing Dilated Cardiomyopathy with Short-Term Doxorubicin Treatment. Acta Cardiol. Sin. 2012, 28, 236-240.

41. Wided, K.; Hassiba, R.; Mesbah, L. Polyphenolic fraction of Algerian propolis reverses doxorubicin induced oxidative stress in liver cells and mitochondria. Pak. J. Pharm. Sci. 2014, 27, 1891-1897. [PubMed]

42. Mattila, M.; Koskenvuo, J.; Söderström, M.; Eerola, K.; Savontaus, M. Intramyocardial injection of SERCA2a-expressing lentivirus improves myocardial function in doxorubicin-induced heart failure. J. Gene Med. 2016, 18, 124-133. [CrossRef] [PubMed]

43. Li, Y.; Eisner, D.A.; O'Neill, S.C. Do calcium waves propagate between cells and synchronize alternating calcium release in rat ventricular myocytes? J. Physiol. 2012, 590, 6353-6361. [CrossRef] [PubMed]

44. Pecoraro, M.; Verrilli, V.; Pinto, A.; Popolo, A. Role of connexin 43 in cardiovascular diseases. Eur. J. Pharmacol. 2015, 768, 71-76.

45. Hervé, J.C.; Derangeon, M.; Sarrouilhe, D.; Giepmans, B.N.; Bourmeyster, N. Gap junctional channels are parts of multiprotein complexes. Biochim. Biophys. Acta 2012, 1818, 1844-1865. [CrossRef] [PubMed]

46. Spray, D.C.; Hanstein, R.; Lopez-Quintero, S.V.; Stout, R.F., Jr.; Suadicani, S.O.; Thi, M.M. Gap junctions and Bystander Effects: Good Samaritans and executioners. Wiley Interdiscip. Rev. Membr. Transp. Signal 2013, 2, 1-15. [CrossRef] [PubMed]

47. Gadicherla, A.K.; Wang, N.; Bulic, M.; Agullo-Pascual, E.; Lissoni, A.; De Smet, M.; Delmar, M.; Bultynck, G.; Krysko, D.V.; Camara, A.; et al. Mitochondrial Cx43 hemichannels contribute to mitochondrial calcium entry and cell death in the heart. Basic Res. Cardiol. 2017, 112, 27. [CrossRef] [PubMed]

48. Azarashvili, T.; Baburina, Y.; Grachev, D.; Krestinina, O.; Evtodienko, Y.; Stricker, R.; Reiser, G. Calcium-induced permeability transition in rat brain mitochondria is promoted by carbenoxolone through targeting connexin43. Am. J. Physiol. Cell Physiol. 2011, 300, C707-C720. [CrossRef] [PubMed]

49. Boengler, K.; Ungefug, E.; Heusch, G.; Leybaert, L.; Schulz, R. Connexin 43 impacts on mitochondrial potassium uptake. Front. Pharmacol. 2013, 4, 73. [CrossRef] [PubMed]

50. Miro-Casas, E.; Ruiz-Meana, M.; Agullo, E.; Stahlhofen, S.; Rodríguez-Sinovas, A.; Cabestrero, A.; Jorge, I.; Torre, I.; Vazquez, J.; Boengler, K.; et al. Connexin43 in cardiomyocyte mitochondria contributes to mitochondrial potassium uptake. Cardiovasc. Res. 2009, 83, 747-756. [CrossRef] [PubMed] 
51. Waza, A.A.; Andrabi, K.; Hussain, M.U. Protein kinase C (PKC) mediated interaction between conexin43 (Cx43) and $\mathrm{K}(+)(\mathrm{ATP})$ channel subunit (Kir6.1) in cardiomyocyte mitochondria: Implications in cytoprotection against hypoxia induced cell apoptosis. Cell Signal. 2014, 26, 1909-1917. [CrossRef] [PubMed]

52. Freireich, E.J. The future of clinical cancer research in the next millennium. Clin. Cancer Res. 1997, 3, 2563-2570. [PubMed]

53. Sardão, V.A.; Oliveira, P.J.; Holy, J.; Oliveira, C.R.; Wallace, K.B. Doxorubicin-induced mitochondrial dysfunction is secondary to nuclear p53 activation in H9c2 cardiomyoblasts. Cancer Chemother. Pharmacol. 2009, 64, 811-827. [CrossRef] [PubMed]

54. Marzocco, S.; Popolo, A.; Bianco, G.; Pinto, A.; Autore, G. Pro-apoptotic effect of methylguanidine on hydrogen peroxide-treated rat glioma cell line. Neurochem. Int. 2010, 57, 518-524. [CrossRef] [PubMed]

55. Boengler, K.; Dodoni, G.; Rodriguez-Sinovas, A.; Cabestrero, A.; Ruiz-Meana, M.; Gres, P.; Konietzka, I.; Lopez-Iglesias, C.; Garcia-Dorado, D.; Di Lisa, F.; et al. Connexin 43 in cardiomyocyte mitochondria and its increase by ischemic preconditioning. Cardiovasc. Res. 2005, 67, 234-244. [CrossRef] [PubMed]

56. Popolo, A.; Piccinelli, A.L.; Morello, S.; Sorrentino, R.; Osmany, C.R.; Rastrelli, L.; Pinto, A. Cytotoxic activity of nemorosone in human MCF-7 breast cancer cells. Can. J. Physiol. Pharmacol. 2011, 89, 50-57. [CrossRef] [PubMed]

57. Montaigne, D.; Hurt, C.; Neviere, R. Mitochondria death/survival signaling pathways in cardiotoxicity induced by anthracyclines and anticancer-targeted therapies. Biochem. Res. Int. 2012, 2012, 951539. [CrossRef] [PubMed]

(C) 2017 by the authors. Licensee MDPI, Basel, Switzerland. This article is an open access article distributed under the terms and conditions of the Creative Commons Attribution (CC BY) license (http:/ / creativecommons.org/licenses/by/4.0/). 